\title{
Resenha
}

\section{Religious Tourism and Pilgrimage Management}

\author{
Maximiliano E. Korstanje ${ }^{1}$
}

\section{Libro:}

RAJ, Razaq e MORPETH, Nigel D. Religious Tourism and Pilgrimage Management. 2nd edition. 2015. Wallingford, CAB International. England. ISBN 978-178064523-0, pp. 342.

Palabras clave: Turismo religioso; Gestión de peregrinos.

En los últimos años, la religión ha estado en la agenda de los medios masivos de comunicación, ya sea como eje central de una serie de conflictos materializados o canalizados por el terrorismo, o como las imposibilidades de una institución medieval cuyos problemas radican en cierta imposibilidad para dar respuestas a las necesidades de sus feligreses. Durante mucho tiempo se pensaba que la industrialización capitalista traería consigo la muerte irreducible de la religión, pero lejos de eso, una mayor cantidad de personas se disponen a viajar a centros de peregrinajes y hacen turismo religioso en todo el mundo. Dean MacCannell enfatizaba en el turismo como una continuación de la religión. Si para el mundo indígena el tótem confiere a la comunidad de cierta protección e identidad, misma función ejerce el turismo en la sociedad moderna. Empero dentro de este esquema, ¿donde ubicamos al turismo religioso?, ¿es este fenómeno una prueba de descomposición social como anticipaba MacCannell (1976) o una realidad insoslayable que la religión aún juega un rol importante en la sociedad?

En su nueva edición (segunda) los profesores Razaq Raj \& Kevin Griffin ofrecen en Religious tourism and Pilgrimage Management, ciertas respuestas a los interrogantes anteriormente formulados. Si bien, los editores reconocen que el turismo y la religiosidad han estado históricamente ligados, no menos cierto es que un debate profundo respecto a sus respectivas naturalezas e intereses se torna cada vez más necesario. En un sentido, mientras el turista se mueve por curiosidad, el peregrino parte de una carencia que intenta llenar. Por lo pronto,

\footnotetext{
${ }^{1}$ Docente da Universidad de Palermo, Argentina e membro da International Society for Philosophers, Sheffield, England. E-mail: maxikorstanje@arnet.com.ar
} 
dicha incongruencia ha sido clave en la tensión que se observa en ciertos destinos internacionales respecto a los visitantes motivados por cuestiones de fe de aquellos que buscan consumir cultura.

La primera sección del trabajo apuntala 6 capítulos conceptuales en donde se discute al turismo religioso desde un lineamiento amplio. Si bien lo sagrado confiere un aura de excepcionalidad al lugar visitado, turismo y religiosidad comparten la necesidad de una experiencia la cual comercializada o no puede ser ofrecida para la promoción del lugar. Por ende, se da una suerte de "globalización del los espacios" que merece ser estudiado. En este intercambio de experiencias, el terrorismo, sin lugar a dudas, representa no solo una amenaza para el turismo religioso sino para la industria en sí. El acto de viajar requiere de cierta infraestructura para la concreción del mismo además de la confianza necesaria para que el huésped sea protegido por el anfitrión. Precisamente, es sobre este mensaje dialéctico que opera el terrorismo. La vulnerabilidad de los extranjeros afecta la legitimidad de los estados que deben protegerlos. Aun cuando el fenómeno de la violencia contra los peregrinos no es nuevo implica un mensaje para los estados nacionales y para otros viajeros que puede afectar la atractividad del sitio.

En la segunda sección, los editores exploran el complejo mundo de la experiencia psicológica del peregrinaje. Comprender el fenómeno desde la plasticidad de la experiencia es clave para construir un modelo sobre los diferentes productos, sus opciones, limitaciones y las expectativas que generan. El consumidor define sus actos de compra en base a la "expectativa" que espera del producto. Estos imaginarios encarnan diversas motivaciones pero pueden agruparse en dos grandes grupos. Aquellas teorías asociadas al contenido o a los procesos. Las primeras buscan comprender la motivación de acuerdo a los factores exógenos que producen motivación en el consumidor. La tesis de Abraham Maslow o los factores de Herzberg son algunas de este subtipo o familia de teorías. En segundo lugar, las teorías procesuales intentan explicar la motivación por medio de la interacción de variables en contextos complejos, a la vez que delinean el grado de influencia que mantiene el sujeto a esta interacción.

El tercer apartado contiene una serie de capítulos empíricos que dotan al lector de casos prácticos sobre turismo religioso en todo el mundo. Esta sección, en lo particular, además de descriptiva es rica en contenido para estudiantes o profesionales del sector. Desde lo 
conceptual hacia lo empírico, el libro reseñado ofrece un argumento consolidado que intenta abordar tres ejes centrales del turismo religioso, la atractividad del sitio por medio del binomio sagrado-profano, la interacción de la experiencia con esa idea de sacralidad y las diferentes expresiones de peregrinaje que se practican en el mundo. Sin lugar a dudas, los esfuerzos de los profesores Raj y Griffin han dado como fruto una extensa obra que los consolida a ambos como especialistas mundiales de renombre respecto al turismo religioso.

Cabe aclarar que en tanto que ritual de pasaje que produce un quiebre identitario, el turismo y la religión se encuentran estrechamente unidos (Korstanje 2009; Cardona, Criado, Cantallops 2015). La misma idea de carga y reparación se encuentra presente en los textos bíblicos originales. En trabajos anteriores, Korstanje \& Busby han discutido extensamente que el turismo, como ritual, intenta "recuperar ese paraíso perdido" del cual nos hablan los textos sagrados. La idea misma de pecado y perdón intenta emular la lógica del trabajo y del ocio. Al punto en el cual, el pecado es comprendido como una carga es que el perdón sugiere un alivio. De la misma manera, trabajamos sujetos a la regla social para luego lanzarnos a la indisciplina -codificada- que nos ofrece el ocio. Si prestamos atención a los elementos de la naturaleza que se encuentran en la mayoría de los rituales de pasaje, agua y fuego, ambos se transmutan en forma de sol y mar como requisitos fundamentales para los turistas que disfrutan en sus vacaciones (Korstanje \& Busby 2010). Tal vez por la importancia antropológica que tiene el turismo (como el ocio) para la sociedad moderna (MacCannaell 1976), es que se haya transformado en el objetivo central del terrorismo internacional.

\section{Referencias}

CARDONA, J. R., CRIADO, M. D. C. A., CANTAlloPS, A. S. El Míto del Paraiso perdido en la definición del destino turístico. Estudios y Perspectivas en Turismo, v. 24. n. 3. p. 697-717. 2015

KORSTANJE, M. Interpretando el Génesis del Descanso: una aproximación a los mitos y rituales del turismo. Pasos. Revista de Turismo y Patrimonio Cultural, v.7. n.1. p. 99-113. 2009.

KORSTANGE, M., \& BURBY, G. "Understanding the Bible as the roots of physical displacement: the origin of tourism". E-Review of Tourism Research, v.8. n.3. p. 95-111. 2010.

MACCANNELL, D. The tourist: A new theory of the leisure class. Berkeley, University of California Press. 1976.

\section{Recebido em: 22/11/2015}

Aprovado em: 20/04/2016 